\title{
Development of soil moisture measurement with wireless sensor web-based concept
}

\author{
Julham ${ }^{1}$, Hikmah Adwin Adam², Arif Ridho Lubis ${ }^{3}$, Muharman Lubis ${ }^{4}$ \\ 1,2,3 Department of Computer Engineering and Informatics, Politeknik Negeri Medan, Indonesia \\ ${ }^{4}$ School of Industrial Engineering, Telkom University, Indonesia
}

\begin{tabular}{l} 
Article Info \\
\hline Article history: \\
Received Sep 4, 2018 \\
Revised Nov 5, 2018 \\
Accepted Nov 19, 2018 \\
\hline
\end{tabular}

Keywords:

Input

Sensor

Topology

Wireless

\begin{abstract}
Measurement of soil moisture commonly by applying the soil moisture sensors is to measure the condition of the ground around which is relatively not wide. Therefore if applied for the large-scale, repeated measurements are required in accordance with the determined point. As a result it takes time to get the whole results. With the existence of wireless sensor technology then this problem can be overcome. This wireless sensor system will create a network consisting of nodes and server. In this study the server part is a server computer that requires a web server application together with its script to display and store data, while the node part is the data reader system. In the data system reader module, the sensor device is required as the input that is SEN0114, the processor is a microcontroller, while the wireless uses Wi-Fi module that is ESP8266. Wi-Fi topology used later is infrastructure (using access points). In this research, it begins by testing the sensor and then testing the data validation between the node and the server. SEN0114 sensor has different value from the American Standard Method (ASM) that is $0.922 \%$. While the data validation test of the measurement result is Wi-Fi ESP8266 module which has a maximum distance of 14 meters toward the access points.
\end{abstract}

Copyright $(0) 2019$ Institute of Advanced Engineering and Science. All rights reserved.

\section{Corresponding Author:}

Julham,

Department of Computer Engineering and Informatics,

Politeknik Negeri Medan,

Jalan Almamater No. 1, 20155, Medan, North Sumatera, Indonesia.

Email: julham.19761212@ polmed.ac.id

\section{INTRODUCTION}

Soil is an ideal growing medium for plants, thus they will flourish and have good productivity if planted on it. Moisture factor is very important for the soil for the weathering process of minerals and organic matters, as well as a medium of nutrient for the roots of the plant. However, if it is too humid the movement of air within the soil will be restricted, preventing the roots of the plants from getting oxygen causing death [1-3]. To find out the information of the soil moisture is conducted by directly measuring it by applying the sensor. Stevanus and his colleagues in 2013 conducted a study entitled "Ground-based soil moisturebased microcontroller PIC 16F84". This study applied a soil moisture sensor consisting of two stainless steel metal rods functioning as a capacitor with the ground as the dielectric. With the help of the signal generator, the two metal rods inserted into the ground will produce a change in the capacitance value (impedance) [4]. This value is processed by microcontroller to display on LCD or seven segments. Similarly, Suhendri and his colleagues conducted a research in 2015 about the application of soil moisture sensor with two metal bars to the cayenne pepper plant in order that the moisture can be controlled by using microcontroller ATMEGA microcontroller [5]. It showed that the concluded that the soil moisture measurement results still involve one sensor of soil moisture and the data cannot be stored. Thus the researchers tried to develop the existing measurement by applying a wireless sensor concept with WiFi media. 
This concept is expected to measure large-scale area, as well as to monitor the fluctuations of changes and store data in the computer server. Therefore, there are several objective for this study, which to design a configuration of a wireless based device to measure the ground moisture. Then, to compare the measurement results between sensors and soil moisture measurements referring to the American Standard Method (ASM). Lastly, to measure the maximum distance between nodes (sensors) and servers where data can still be read on the server. After completed the objectives, it is expected to measure, monitor and store soil moisture data for small and large scale areas, such as plantations by deploying these sensor modules, it also can optimize the use of Wi-Fi which is only for the use of computer and mobile applications, then it can be used for microcontroller applications (related to the sensor). Afterwards, it can provide additional learning module for interfacing course about application of microcontroller. Soil moisture is a key state variable in the terrestrial system as it controls the exchange of water and energy between the land surface and the atmosphere [8]. Therefore, rapid measurement technique using electronic sensors such as time domain reflectometers, capacitance, impedance and dielectric sensors offer an alternative to destructive and time consuming gravimetric sampling [9]. Meanwhile, soil water content (SWC) affects water infiltration, redistribution, percolation, evaporation, and plant transpiration [18]. Soil moisture content has paramount importance in dictating engineering, agronomic, geological, ecological, biological and hydrological characteristics of the soil mass. Though earlier researchers have employed various techniques of moisture content determination of soils, both in laboratory and in situ conditions, ascertaining the applicability of these techniques to soils of entirely different characteristics and the 'types of moisture content', which they can measure, is still a point of debate [19].

\section{LITERATURE REVIEW}

\subsection{Soil Moisture}

Soil moisture is water that fills part or all of the soil pores above the water table. Another definition says that the soil moisture states the amount of water stored between the pores of the soil, which is very dynamic. It is caused by evaporation through the soil surface, transpiration and percolation. Soil water content is stated in percent volume i.e. percentage of water volume to soil volume. This method is very beneficial because it can figure out availability of water for the crop at a given volume of soil. The method of determining the moisture content can be done by using a number of wet soils dried in the oven at a temperature of $1000 \mathrm{C}-1100 \mathrm{C}$ for a certain time. The disappeared water due to drying process is the amount of water contained in the soil. The irrigation water entering the ground initially replaces the air in the macro pore and then the micro pores. The amount of water moving through the soil is related to the size of the pores in the soil. The next additional water will move down through the process of saturating water movements. Water movement not only happens vertically but also horizontally. The force of gravity has no effect on the horizontal movement. The uncertainty regarding the influence of soil moisture variability on atmospheric parameters on smaller scales concerns (a) operational forecast models, where soil moisture is often treated as a numerical parameter to constrain modelled $2 \mathrm{~m}$ temperature and humidity fields to observations, and (b) field observations, where the uncertainty of temporal and spatial soil moisture variability and its influence on atmospheric variables is high, as soil moisture is not directly operationally measured on a larger grid [11]. To identify the soil moisture condition can be measured by applying either soil moisture meter i.e. Soil Tester or manual calculation to know soil moisture referring to American Standard Method (ASM). Suppose MA = mass of water, MTB = mass of wet soil, MTK = mass of dry ground, and KT = soil moisture, the equations which can be used to find soil the moisture are showed by (1) and (2) [4].

$$
\begin{aligned}
& \mathrm{MA}=\mathrm{MTB}-\mathrm{MTK} \\
& \mathrm{KT}=\mathrm{MA} / \mathrm{MTK} \times 100 \%
\end{aligned}
$$

\subsection{Sensor SEN0114}

Moisture Sensor SEN0114 is a special moisture sensor specifically used for ground with the help of software having three outputs i.e. Ground (GND), Power (V) and (Vs). This sensor works with the amount of water content in the soil. Applying two conductors is aimed to pass the current through the ground, so that it is very sensitive to the electrical charge. The operational voltage of the Moisture Sensor is between 3.3 Volts to 5 Volts DC, whereas the output voltage ranges from $0 \sim 4.2$ Volts and the resulting current is $35 \mathrm{~mA}$. The size of the SEN0114 Moisture Sensor is $60 \times 20 \times 5 \mathrm{~mm}$. The value determination of this sensor measurement is (value range) $0 \sim 300$ for dry soil, $300 \sim 700$ for moist soil, and $700 \sim 950$ in water [5]. However, this sensor has limitation, which are low tech, has exposed electronics and does not appear to be 
waterproof. This sensor measures electrical conductivity as a proxy for volumetric water content (VWC). Which makes the sensors extremely sensitive to salts in the substrate or soil $[10,12]$.

\subsection{Soil Moisture Meter}

It is a very simple soil moisture circuit, using two electrodes that act as sensors. Soil as a system can be modeled by the properties of dielectric, semi-isolator and porosity. When between the conductors is inserted the dielectric material will occur dipole in the material, where the charge distribution will accumulate at the dielectric ends, while the material will not happen the flow of electric current $(i=0)$ [5-6]. Resistivity measurements at adequate depths should be made if an accurate calculation of the induced parameters on the pipeline is needed [13]. The greater the volume compared with the volume of the electrode, the more efficient is the electrode [16]. Selection of sensor for a particular application or on the basis of type of soil can become a tiresome exercise as there are wide level of soil moisture sensors available in the market. The advantages and disadvantages of sensors must be considered as criteria for selection because the working principle behind each type of sensor varies with its application and type of soil [17]. Sensor SEN0114 as shown in Figure 1.

It is a very simple soil moisture circuit, applying two electrodes functioning as the sensors. Soil as a system can be modeled by the properties of dielectric, semi-isolator and porosity. When the dielectric material is inserted between the conductors, dipole will occur in the material, where the charge distribution will accumulate on the dielectric point, while the flow of electric current will not occur on the material $(i=0)$ [7]. Device of measuring soil moisture as shown in Figure 2.

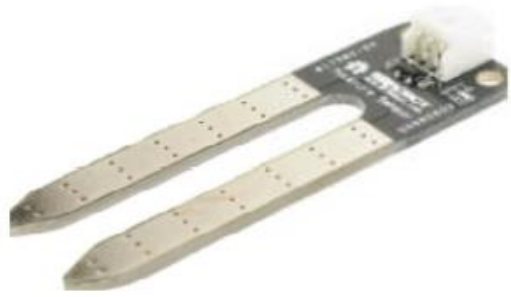

Figure 1. Sensor SEN0114

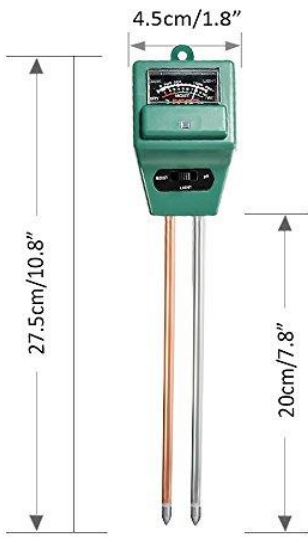

Figure 2. Device of measuring soil moisture

\subsection{ESP8266 Wi-Fi Module}

ESP8266 is a Wi-Fi module functioning as a microcontroller enhancement like Arduino to connect directly to Wi-Fi and create TCP / IP connections. This module requires about 3.3v power by having three Wi-Fi modes namely Station, Access Point and Both (both of them) [1]. This module is also completed with a processor, memory and GPIO where the number of pins depends on the type of ESP8266 used. Consequently this module can stand alone without using any microcontroller because it has such equipment as microcontroller. Wi-Fi Module as shown in Figure 3.

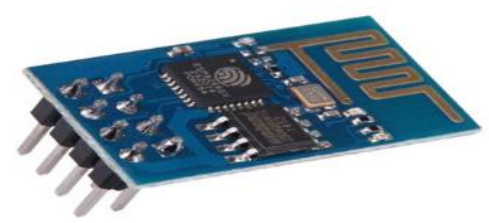

Figure 3. ESP8266 Wi-Fi Module 


\subsection{Web Server}

Server or Web server is a software that provides data-based services and functions to receive requests from HTTP or HTTPS on known clients and is usually known as web browser (Mozilla Firefox, Google Chrome) and to send back the results in the form of multiple web pages and will generally be in the form of an HTML document. The main function of the Server or Web server is to perform or to transfer the user's request files through a pre-defined communication protocol. The requested web page consists of text files, videos, images, files and more. The utilization of web server is to transfer all aspects of filing in a web page including those in the form of text, video, images and more. One example of a Web Server is Apache. Apache (Apache Web Server - The HTTP Web Server) is the most widely used on the Internet. The program was first designed for UNIX environment operating systems. Apache has a lot of support programs. This provides a fairly complete service for its users. Some Apache supports:

a) Access Control

This control can be run by the host name or IP CGI number (Common Gateway Interface) The most famous is perl (Practical Extraction and Report Language), supported by Apache by placing it as modul (mod_perl).

b) PHP (Personal Home Page / PHP Hypertext Processor)

A programs with a kind of CGI method, which processes the text and works on the server. Apache supports PHP by placing it as one of its modules (mod_php). This makes PHP performance even better compare the other script languanges.

c) SSI (Server Side Includes)

The Apache web server has advantages over the following considerations:

1) Apache is included in the category of freeware.

2) Apache is easy to install.

3) Apache is able to operate on various operating system platforms.

4) Easy to configure.

5) Apache has only four configuration files.

6) Easy to add other peripherals to the web server platform

\section{RESEARCH METHODOLOGY}

The sensor system made in this research is still in the form of prototype because it has not been equipped with protective container, as shown in Figure 6, which left side consists of display module ie LCD and 9VDC battery, while the right side consists of microcontroller module, WiFi module and moisture sensor module (moisture sensor). System block diagram as shown in Figure 4 and system block diagram as shown in Figure 5.

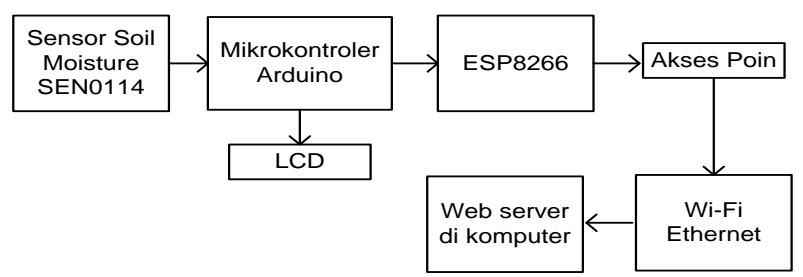

Figure 4. System block diagram

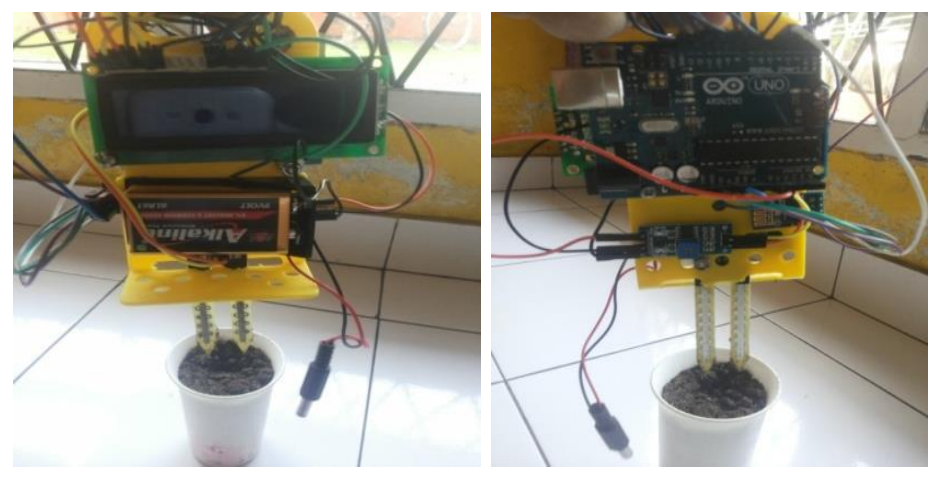

Figure 5. Front and back side view 


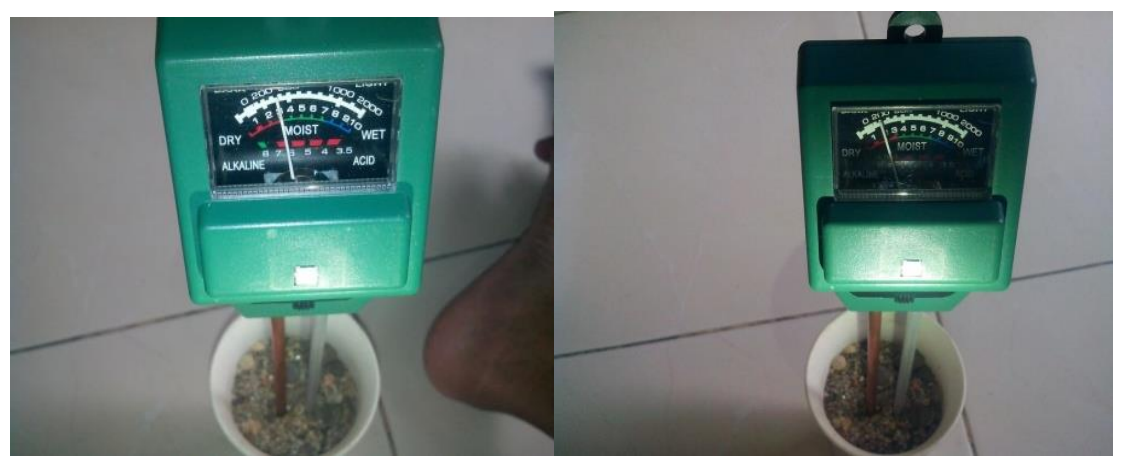

Figure 6. Measurement results for wet soil mass 475 grams (left) and 425 grams (right)

\section{DISCUSSION AND RESULTS}

\subsection{Sensor Testing}

Before the test is made, the determination of soil moisture condition category is created as follows:

a) The category condition of the soil moisture is dry if the value generated by the sensor in percent is $0 \%$ $50 \%$ or in the form of value is $515.5-1023$.

b) The category condition of the soil moisture is moist if the value generated by the sensor in percent is $51 \%-100 \%$ or in the form of a value is $0-501.27$.

The steps taken are as follows:

1) Firstly, the sand textured soil is placed on paper and then heated by using with a grill from gas.

2) Next it is baked until the water is lost, as showed that the paper as the container is not wet anymore.

3) After that preparing a container to place it i.e. a plastic cup. The cup is should be empty and be placed on the top of the digital scale to obtain the initial conditions of weighing.

4) Then fill the cup with 350 gram soil.

Table 1 it can be seen that the average difference of measurement result of tool made towards American Standard Method is $1.03 \%$. So that it can be interpreted that Soil Moisture sensors SN0114 can measure the soil moisture with a relatively good measurement results. The next test is performed between the sensors with moisture meter. Some photos of the obtained measurements are shown in Figure 6. From Table 2 it can be seen that the average difference of the measurement result of the tool made to the manufacturer moisture meter is $1.86 \%$. First form of validation test as shown in Table 3. Second form of validation test as shown in Table 4.

Table 1. Comparison between ASM and Sensor

\begin{tabular}{|c|c|c|c|c|}
\hline \multirow{2}{*}{$\begin{array}{l}\text { Mass of dry soil } \\
\text { (gr) }\end{array}$} & \multirow{2}{*}{$\begin{array}{c}\text { Mass of wet } \\
\text { soil (gr) }\end{array}$} & \multicolumn{2}{|c|}{ Soil moisture (\%) } & \multirow{2}{*}{$\begin{array}{c}\text { Different } \\
\text { measurement }\end{array}$} \\
\hline & & ASM & Sensor & \\
\hline 350 & 375 & 7,14 & 8 & 0,86 \\
\hline 350 & 400 & 14,29 & 13 & 1,29 \\
\hline 350 & 425 & 21,42 & 22 & 0,58 \\
\hline 350 & 450 & 28,57 & 28 & 0,57 \\
\hline 350 & 475 & 35,71 & 34 & 1,71 \\
\hline 350 & 500 & 42,86 & 43 & 0,14 \\
\hline 350 & 525 & 50 & 51 & 1 \\
\hline 350 & 550 & 57,14 & 58 & 0,86 \\
\hline 350 & 575 & 64,29 & 65 & 0,71 \\
\hline 350 & 600 & 71,43 & 72 & 0,57 \\
\hline 350 & 625 & 78,57 & 77 & $1 ., 57$ \\
\hline 350 & 650 & 85,71 & 85 & 0,71 \\
\hline 350 & 675 & 92,86 & 91 & 1,86 \\
\hline \multirow[t]{2}{*}{350} & 700 & 100 & 98 & 2 \\
\hline & & \multicolumn{2}{|c|}{ Average of difference } & 1,03 \\
\hline
\end{tabular}


Table 2. Comparison of Moisture Meter with Sensor

\begin{tabular}{|c|c|c|c|c|}
\hline \multirow{2}{*}{$\begin{array}{l}\text { Mass of dry soil } \\
\text { (gr) }\end{array}$} & \multirow{2}{*}{$\begin{array}{c}\text { Mass of wet } \\
\text { soil (gr) }\end{array}$} & \multicolumn{2}{|c|}{ Soil moisture (\%) } & \multirow{2}{*}{$\begin{array}{c}\text { Different } \\
\text { measurement }\end{array}$} \\
\hline & & Moisture meter & Sensor & \\
\hline 350 & 375 & 6 & 8 & 2 \\
\hline 350 & 400 & 15 & 13 & 2 \\
\hline 350 & 425 & 20 & 22 & 2 \\
\hline 350 & 450 & 24 & 28 & 4 \\
\hline 350 & 475 & 30 & 34 & 4 \\
\hline 350 & 500 & 40 & 43 & 3 \\
\hline 350 & 525 & 50 & 51 & 1 \\
\hline 350 & 550 & 59 & 58 & 1 \\
\hline 350 & 575 & 66 & 65 & 1 \\
\hline 350 & 600 & 70 & 72 & 2 \\
\hline 350 & 625 & 78 & 77 & 1 \\
\hline 350 & 650 & 85 & 85 & 0 \\
\hline 350 & 675 & 90 & 91 & 1 \\
\hline \multirow[t]{2}{*}{350} & 700 & 100 & 98 & 2 \\
\hline & & \multicolumn{2}{|c|}{ Averange Differences } & 1,86 \\
\hline
\end{tabular}

Table 3. First form of Validation Test

\begin{tabular}{cccc}
\hline No. & $\begin{array}{c}\text { Distance } \\
\text { (meter) }\end{array}$ & Status & $\begin{array}{c}\text { Time to Receive Data } \\
\text { (second) }\end{array}$ \\
\hline 1 & 1 & Connected & 3,59 \\
2 & 2 & Connected & 3,61 \\
3 & 4 & Connected & 3,70 \\
4 & 6 & Connected & 3,83 \\
5 & 8 & Connected & 4,10 \\
6 & 10 & Connected & 4,35 \\
7 & 12 & Connected & 4,78 \\
8 & 14 & Connected & 5,51 \\
9 & 16 & Connected & Not respond \\
10 & 18 & Connected & Not respond \\
\hline
\end{tabular}

Table 4. Second form of Validation Test

\begin{tabular}{cccc}
\hline No. & $\begin{array}{c}\text { Distance } \\
\text { (meter) }\end{array}$ & Status & $\begin{array}{c}\text { Time to Receive Data } \\
\text { (second) }\end{array}$ \\
\hline 1 & 1 & Connected & 3,51 \\
2 & 2 & Connected & 3,60 \\
3 & 4 & Connected & 3,73 \\
4 & 6 & Connected & 3,90 \\
5 & 8 & Connected & 4,13 \\
6 & 10 & Connected & 4,34 \\
7 & 12 & Connected & 4,70 \\
8 & 14 & Connected & 4,84 \\
9 & 16 & Connected & 5,12 \\
10 & 18 & Connected & 5,52 \\
11 & 20 & Connected & 5,92 \\
12 & 22 & Connected & 6,13 \\
13 & 24 & Connected & 6,83 \\
14 & 26 & Connected & 7,50 \\
15 & 28 & Connected & Not respond \\
16 & 30 & Connected & Not respond \\
\hline
\end{tabular}

\subsection{Testing of Submit Data}

Every time there is a change in distance, the sensor system is turned off first and after that the sensor system is moved according to the desired distance. Then revive the sensor system. After that observation on the server is done. In this test is the validation of data sent by the sensor system and data received by the server. This test is done in two forms, i.e.

a) Validation by moving the sensor system (consisting of Arduino, sensor moisture, ESP8266) with varying distance to access point and server devices, as shown in Figure 6. If any distance changes then the sensor system is turned off first and then transfer the sensor system according to the desired distance. Then turn on the sensor system. Then observe it on the server.

b) Validation by moving the server with varying distance to the access point device and sensor system, If any distance changes, the sensor system is turned off first and then transfer the sensor system according to the desired distance. Then turn on the sensor system. Then observe it on the server. 


\section{CONCLUSION}

The measurement of data validation test were varied from the effect of a barrier between sensor systems, access points and servers.

1) Sensor of soil moisture type SEN0114 having different value from American Standard Method (ASM) standard is $1.03 \%$.

2) Soil moisture sensor type SEN0114 having different value with measurement device moisture meter is $1.86 \%$.

3) The ESP8266 device is a wireless network device that can be applied by Arduino to transmit soil moisture data.

4) Data validation Test on the second part still provide a response at a distance of 16 meters while in the first part does not respond.

5) The program applied for Arduino is AVR Basic Compiler software, while on the server side applied PHP software, MySQL as its database.

\section{REFERENCES}

[1] Fadlur R, Muhammad I. "Implementasi IOT dalam rancang bangun sistem monitoring panel surya berbasis Arduino”. Prosiding SNATIF Ke-3, 2016.

[2] Pusparini A, Kurniawan MA. “Analisa Penanganan Penurunan Tanah di Tanah Mas Semarang Utara”. Bachelor Thesis. Fakultas Teknik Undip. 2008.

[3] Mustafa M. “Dasar-dasar Ilmu Tanah”. Fakultas Pertanian Universitas Hasanudin Makasar, 2012.

[4] Stevanus, Setiadikurnia D. "Alat Pengukur Kelembaban Tanah Berbasis Mikrokontroler PIC 16F84". Indonesian Journal of Applied Physics, 3(1), pp. 1-11, 2013.

[5] Suhendri, Beni I, Tedy R. "Sistem pengontrolan kelembaban tanah pada media tanam cabai rawit menggunakan mikrokontroler ATMEGA16 dengan metode PD (Proportional \& Derivative)". Jurnal Coding Sistem Komputer Untan vol. 3 no. 3, 2015 .

[6] Sugiyono. "Metode penelitian kuantitatif, kualitatif dan R\&D”. Penerbit Alfabeta Bandung, 2017.

[7] Yuliza, Pangaribuan H. "Rancang bangun kompor listrik digital IOT". Jurnal Teknologi Elektro Universitas Mercubuana vol. 7 no. 3, September, 2016.

[8] Vereecken H, Huisman JA, Pachepsky Y, Montzka C, van der Kruk J, Bogena H, Weihermuller L, Herbst M, Martinez G, Vanderborght J. "On the patio-temporal dynamics of soil moisture at the field scale". Journal of Hydrology 516 (2014), pp. 76-96.

[9] Merlin O, Walker JO, Panciera R, Young R, Kalma JD, Kim EJ. "Soil moisture measurement in heterogenous terrain". MODSIM 2007, pp. 2604-2610.

[10] Ferrarezi RS, Dove SK, van Iersel MW. "An Automated System for Monitoring Soil Moisture and Controlling Irrigation Using Low-cost Open-source Microcontrollers". HortTechnology 25(1) 2015, pp. 110-118.

[11] Hauck C, Barthlott C, Krauss L, Kalthoff N. "Soil moisture variability and its influence on convective precipitation over complex terrain”. Quaterly Journal of the Royal Meteorological Society, 137 (2011), pp. 42-56.

[12] Singh R, Singh SP. "Development of a low cost wireless temperature monitoring system of industrial and research application". Int. J. Curr. Eng. Technoogy 5 (2015), pp. 355-361.

[13] El Gayar AI, Abdul-Malek Z, Imran M, Wooi CL, Elshami IF. "Conductive and inductive coupling between faulted power lines and buried pipeline by considering the effect of soil structure". Indonesian Journal of Electrical Engineering and Computer Science (IJEECS), vol. 5(3), pp. 656-660 (2017).

[14] Lubis M, Kartiwi M, Zulhuda S. "Decision to casting a vote: an ordinal regression statistical analysis". IEEE ICT4M 2014.

[15] Lubis AR, Fachrizal F, Lubis M, Thahir HM. "Wireless service at public university: a survey of users perception on security aspects". IEEE ICOIACT 2018.

[16] Samadinasab S, Namdari F, Bakshipor M. "The influence of moisture and temperature on the behavior of soil resistivity in earthing design using finite element method". Indonesian Journal of Electrical Engineering and Computer Science (IJEECS), vol. 2(1), pp. 11-22 (2017).

[17] Garg A, Munoth P, Goyal R. "Application of soil moisture sensors in agriculture: a review". Int. Conf. on Hydraulics, water resources and coastal engineering vol. 21, 2016.

[18] Bittelli M. "Measuring soil water content: a review". HortTechnology 21(3) June 2011, pp.293-300.

[19] Lekshmi S, Singh DN, Baghini MS. "A critical review of soil moisture measurement". Measurement 54(2014), pp. 92-105. 